\title{
A novel permanent gauge-cam station for surface-flow observations on the Tiber River
}

\author{
Flavia Tauro $^{1}$, Andrea Petroselli ${ }^{2}$, Maurizio Porfiri ${ }^{3}$, Lorenzo Giandomenico $^{4}$, Guido Bernardi ${ }^{4}$, Francesco Mele $^{5}$, \\ Domenico Spina $^{5}$, and Salvatore Grimaldi ${ }^{1,3}$ \\ ${ }^{1}$ Dipartimento per l'Innovazione nei Sistemi Biologici, Agroalimentari e Forestali, University of Tuscia, Viterbo 01100, Italy \\ ${ }^{2}$ Dipartimento di Scienze Agrarie e Forestali, University of Tuscia, Viterbo 01100, Italy \\ ${ }^{3}$ Department of Mechanical and Aerospace Engineering, New York University Tandon School of Engineering, \\ 11201 Brooklyn, NY, USA \\ ${ }^{4}$ CAE S.p.a., San Lazzaro di Savena 40068, Italy \\ ${ }^{5}$ Centro Funzionale Regione Lazio, Rome 00145, Italy \\ Correspondence to: Salvatore Grimaldi (salvatore.grimaldi@unitus.it)
}

Received: 1 November 2015 - Published in Geosci. Instrum. Method. Data Syst. Discuss.: 1 February 2016

Revised: 23 May 2016 - Accepted: 31 May 2016 - Published: 22 June 2016

\begin{abstract}
Flow monitoring of riverine environments is crucial for hydrology and hydraulic engineering practice. Besides few experimental implementations, flow gauging relies on local water level and surface-flow velocity measurements through ultrasonic meters and radars. In this paper, we describe a novel permanent gauge-cam station for large-scale and continuous observation of surface flows, based on remote acquisition and calibration of video data. Located on the Tiber River, in the center of Rome, Italy, the station captures 1 min videos every 10 min over an area oriented along the river cross section of up to $20.6 \times 15.5 \mathrm{~m}^{2}$. In a feasibility study, we demonstrate that accurate surface-flow velocity estimations can be obtained by analyzing experimental images via particle tracking velocimetry (PTV). In medium illumination conditions (70-75 lux), PTV leads to velocity estimations in close agreement with radar records and is less affected by uneven lighting than large-scale particle image velocimetry. Future efforts will be devoted to the development of a comprehensive test bed infrastructure for investigating the potential of multiple optics-based approaches for surface hydrology.
\end{abstract}

\section{Introduction}

Understanding the kinematic organization of natural water bodies is central to hydrology and environmental engineering practice (LeCoz et al., 2010). Reliable flow velocity estimations are essential to comprehend flood generation and propagation mechanisms. Continuous flow observations are often required in the investigation of erosion dynamics, sediment transport, and drainage network evolution (Hrachowitz et al., 2013; Montanari et al., 2013). In engineering practice, flood warning systems largely rely on real-time discharge measurements, and flow velocity monitoring is important for the design and management of hydraulic structures, such as reservoirs and hydropower plants (Kantoush et al., 2011).

Traditionally, gauging stations have been equipped with water level meters, and stage-discharge relationships (rating curves) have been established through few direct discharge measurements (Creutin et al., 2003). Only in rare instances, monitoring stations have integrated radar technology for local measurement of surface-flow velocity (Costa et al., 2006; Fulton and Ostrowski, 2008). Establishing accurate rating curves depends on the availability of a comprehensive range of discharge values, including measurements recorded during extreme events. However, discharge values during highflow events are often difficult or even impossible to obtain, thereby hampering the reliability of discharge predictions. 
In the past 10 years, promising advancements in flow monitoring have been put forward due to fully remote opticsbased velocimetry techniques (Muste et al., 2008; Tang et al., 2008; Tauro et al., 2012a, b). Such methodologies enable the estimation of the surface-flow velocity field over extended regions from the relative motion of naturally occurring debris or floaters dragged by the current (Fujita et al., 1997). Surface-flow velocity measurements are typically related to depth-averaged velocity, and discharge is computed from information on the cross section (Alessandrini et al., 2013; Chiu, 1991; Farina et al., 2014; Jodeau et al., 2008; Moramarco et al., 2004; Tazioli, 2011). Among optical approaches, large-scale particle image velocimetry (LSPIV) is an extension of classical particle image velocimetry (PIV) (Adrian, 1991; Raffel et al., 2007). It is based on the acquisition of pairs of images by a digital camera at known acquisition frequency. Such image pairs are then orthorectified, georeferenced, and a high-speed cross-correlation algorithm is implemented to generate velocity maps. The accuracy of the method is highly dependent on the occurrence and visibility of floaters as well as on illumination conditions (Hauet et al., 2008a).

LSPIV implementations have allowed the characterization of flow patterns in river estuaries (Bechle et al., 2012), lakes (Admiraal et al., 2004), and large-scale riverine environments (Hauet et al., 2009). Most frequently, measurements are conducted through ad hoc installations, which include an angled camera to capture extended fields of view and a processing unit to estimate the velocity field (Bradley et al., 2002). Several observations have been performed using mobile configurations, where frame acquisition is enabled by portable stand-alone instruments or trucks (Kim et al., 2008; Dermisis and Papanicolaou, 2009). In Hauet et al. (2008b), continuous and real-time river monitoring was demonstrated through a fixed LSPIV installation located on a roof nearby the Iowa River. To the best of our knowledge, this implementation is the only fixed LSPIV measurement station for continuous monitoring of a river flow. Similar implementations placed underneath bridges and boardwalks have enabled the observation and analysis of selected flood events (Muste et al., 2011; Tsubaki et al., 2011).

These studies have fostered further efforts toward the refinement of optics-based methods for accurate surface-flow measurements. In Tauro et al. (2014b), a modified setup has been proposed to allow for remote digital image acquisition and calibration based on the use of low-power laser modules. This implementation has proved convenient for observations in difficult-to-access environments and during flood events; however, image processing through LSPIV has been found to be highly affected by the occurrence and spatial distribution of tracers. Motivated by promising experimental findings obtained with the mobile setup, herein, we propose a permanent optics-based sensing platform for surface-flow observations. Specifically, we present an innovative experimental gaugecam station featuring remote image acquisition and calibra- tion for continuous observation of surface flows in the Tiber River at Ponte del Foro Italico, in the center of Rome, Italy. The gauge-cam station enables the acquisition of massive video data throughout the year, providing a remarkable test bed to assess the feasibility and validate optics-based flow measurement approaches.

Since December 2014, the gauge-cam station has acquired digital videos that display variable hydraulic regimes, ranging from flood events to low waters, illumination conditions, and sediment loads. In this paper, we focus on three videos recorded in January and February 2015, whose analysis is undertaken through particle tracking velocimetry (PTV) and LSPIV to generate surface-flow velocity field maps in the $20.6 \times 15.5 \mathrm{~m}^{2}$ field of view. Both sets of findings from video data are compared to radar measurements and discussed for future research investigations.

The rest of the paper is organized as follows. In Sect. 2, the pre-existing local gauging station and the proposed novel measurement installation are described. In Sect. 3, we present the research objectives underlying the design of the gauge-cam station along with possible research directions enabled by its installation. In Sect. 4, a representative experimental video is analyzed with two different optics-based approaches. In Sect. 5, we highlight advantages and limitations of our novel gauge-cam station and identify future possible amelioration. Section 6 summarizes concluding remarks.

\section{Experimental station}

The experimental station is located in the urban tract of the Tiber River at Ponte del Foro Italico in the center of Rome, Italy $\left(41^{\circ} 56^{\prime} 22.7^{\prime \prime} \mathrm{N}, 12^{\circ} 29^{\prime} 09.2^{\prime \prime} \mathrm{E}\right)$; see Fig. 1. An existing monitoring station managed by Centro Funzionale - Regione Lazio is located on the same bridge. It includes a ULM $20 \mathrm{ul}-$ trasonic meter and an RVM20 speed surface radar sensor by CAE S.p.a. The ultrasonic meter records water levels proximal to the midspan of the bridge every $15 \mathrm{~min}$. The radar sensor operates in the 0.30 to $15 \mathrm{~m} \mathrm{~s}^{-1}$ velocity range with an accuracy of $\pm 0.02 \mathrm{~m} \mathrm{~s}^{-1}$, and it records surface velocity every $15 \mathrm{~min}$ over an area of some squared centimeters.

The novel gauge-cam station for optic observations is based on the advanced Multi-Hazard System (Mhas) technology developed by CAE S.p.a. for integrated environmental monitoring (www.cae.it). It comprises two units: a central control apparatus and a sensing platform; see Fig. 2. The control unit is equipped with several input ports to coordinate multiple sensing modules. Specifically, the unit interfaces all measurement devices, runs the sensors, receives, and stores real-time data. A solar-cell rechargeable battery technology guarantees the gauge-cam station operation for considerable periods of time and in case of interrupted power. Data are stored in a data logging terminal that allows for locally visualizing measurements and provides rapid computing capacity, using a dual-core processor and the embedded Linux op- 

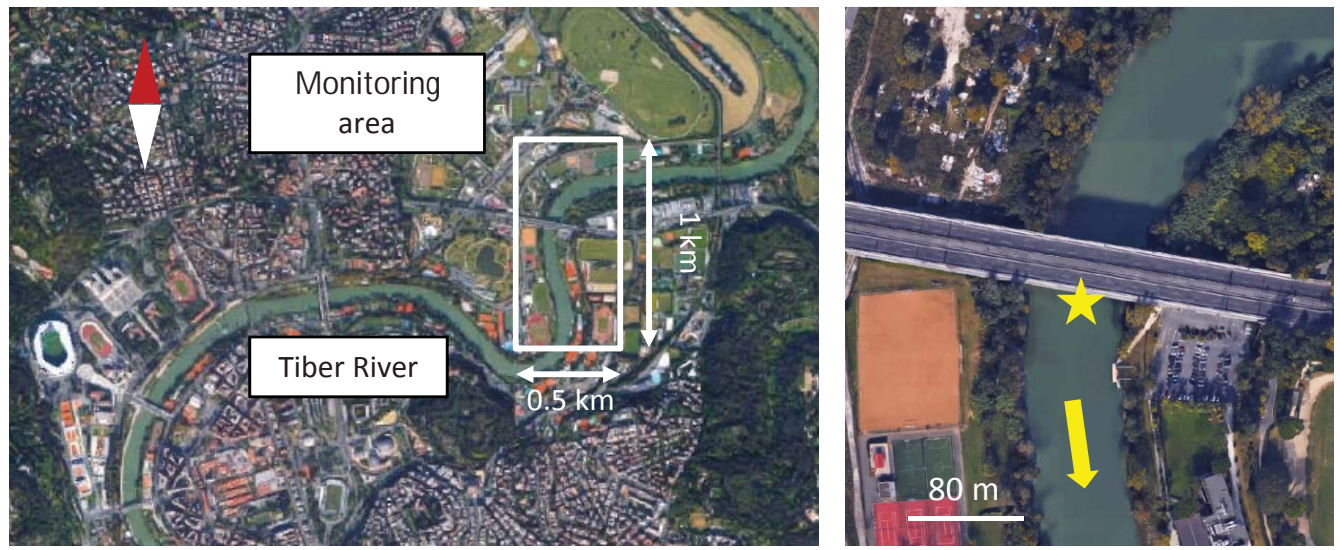

Figure 1. Left: view of the urban tract of the Tiber River - the white box encloses Ponte del Foro Italico. Right: close-up view of the measurement site - the yellow star indicates the location of the gauge-cam station and the yellow arrow shows river flow direction.

erating system. Connection to the unit is established from any web-based device through http communication. By accessing the control unit, users control the station actions, set the events' chaining and time table, edit recording settings, and overlook and potentially download current images. Video storage is enabled through a $1 \mathrm{~Tb}$ solid state external hard drive, which features ext 4 journaling file system for high storage limits.

The sensing unit is based on the portable prototype for LSPIV observations developed in Tauro et al. (2014b). Specifically, it is connected to the control unit and suspended underneath the bridge through an aluminum bar at an elevation of approximately $15 \mathrm{~m}$ from the water surface; see Fig. 2c. All sensors are enclosed in aluminum cases and connected to a $1 \mathrm{~m}$ horizontal aluminum bar. At the center of the horizontal bar, a digital camera is hosted, whereas two $<20 \mathrm{~mW}$ green lasers $(532 \mathrm{~nm}$ in wavelength) are installed at the two ends of the bar, $50 \mathrm{~cm}$ apart from the camera axes. The lasers are diode-pumped solidstate continue-wave modules and are operated at $3 \mathrm{~V}$ and $<300 \mathrm{~mA}$ (http://www.apinex.com, 2015). Each module is encased in a $35 \mathrm{~mm}$ in length and $12 \mathrm{~mm}$ in diameter brass cylinder.

The digital recording system is a Mobotix FlexMount S15 weatherproof internet protocol camera (www.mobotix.com). It is inherently designed for outdoor acquisitions and longtime operation. Specifically, it comprises two miniature optical sensor modules, which are connected to the camera housing through a sensor cable. Two separate rooms host the optical sensors and lenses. The L25 ( $82^{\circ}$ angle-of-view and $4 \mathrm{~mm}$ focal length) and L76 (27 angle-of-view and $12 \mathrm{~mm}$ focal length) optical sensors are located with their axes perpendicular to the water surface to capture the central portion of the river. The higher angle-of-view (L25) sensor allows for acquiring a larger area of the river surface, whereas the lower angle-of-view (L76) sensor synchronously captures finer details in the center of the L25 sensor field of view.
Temporally resolved surface-flow observations at high temporal resolutions are obtained by setting the digital recording system to capture $1 \mathrm{~min}$ long videos every $10 \mathrm{~min}$. The frame acquisition frequency during the recordings is automatically set based on the illumination conditions sensed by the optical sensors, and is limited to a maximum of $12 \mathrm{~Hz}$. Image resolution for both optical sensors is set to $1024 \times 768$ pixels. To enable remote image calibration, the laser modules are operated for $20 \mathrm{~s}$ at the beginning of each video recording. Videos are stored in the MxPEG audio/video container format, which guarantees the stream of good quality images at efficient compression. However, the encoder requires dedicated proprietary software for video conversion to avi and image extraction. Videos are stored through a nestled folding system in the external hard drive.

Specifically, in each folder, several types of data are stored using the MxPEG encoder. Video data are stored as jpg files (not exceeding $17 \mathrm{Mb}$ each), the first frame of each video is saved as a lighter jpf file, and information on the recording settings are contained in light INFO.jpg files (readable with text editing software). In Fig. 3, a representative video frame is displayed. In the top left, the station identification name (Foro Italico) and illuminance intensity (in lux) for both optical sensors are reported. In the top right, date and time of the day (in the format: year-month-day, time zone abbreviation, hours:minutes:seconds) are illustrated. In the bottom left and right, acronyms related to the station internal protocol for sensor triggering and recording are shown. For clarity, on the right-side image, we also report the field of view captured with the left-side optical sensor and the radar-focused area.

\section{Research objectives}

The overarching objective of installing a permanent gaugecam station is to demonstrate a novel, transformative ap- 

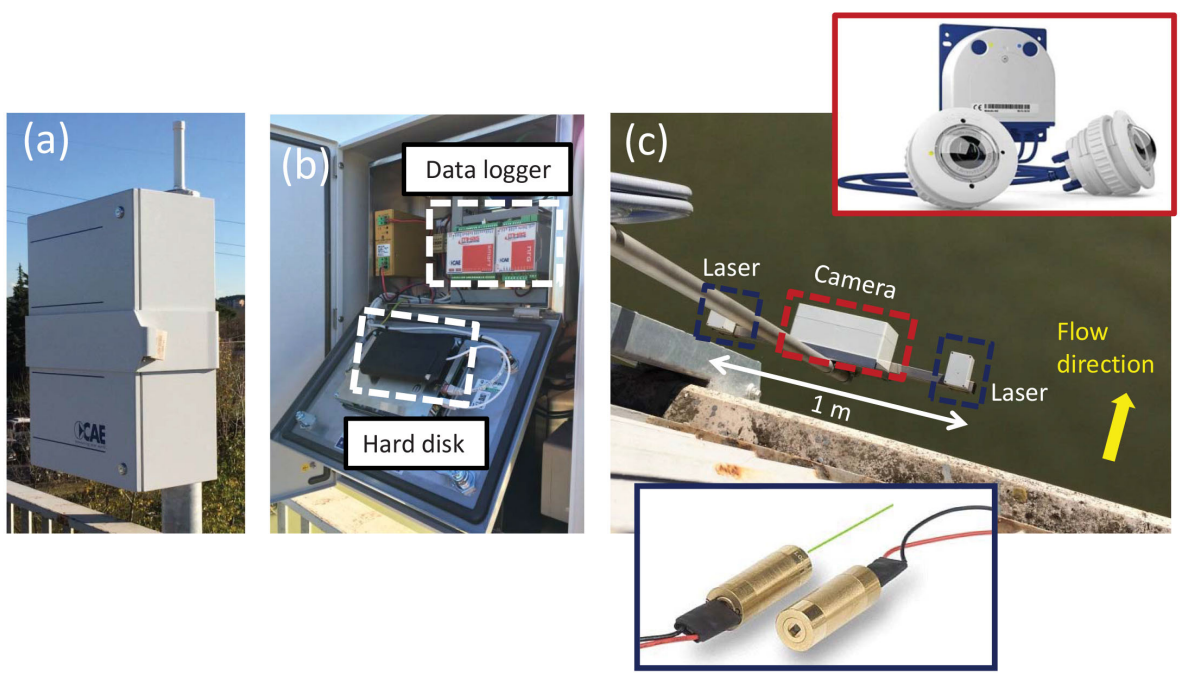

Figure 2. Components of the gauge-cam station including (a) the control unit, (b) data logging terminal, and (c) sensing unit with camera and lasers.

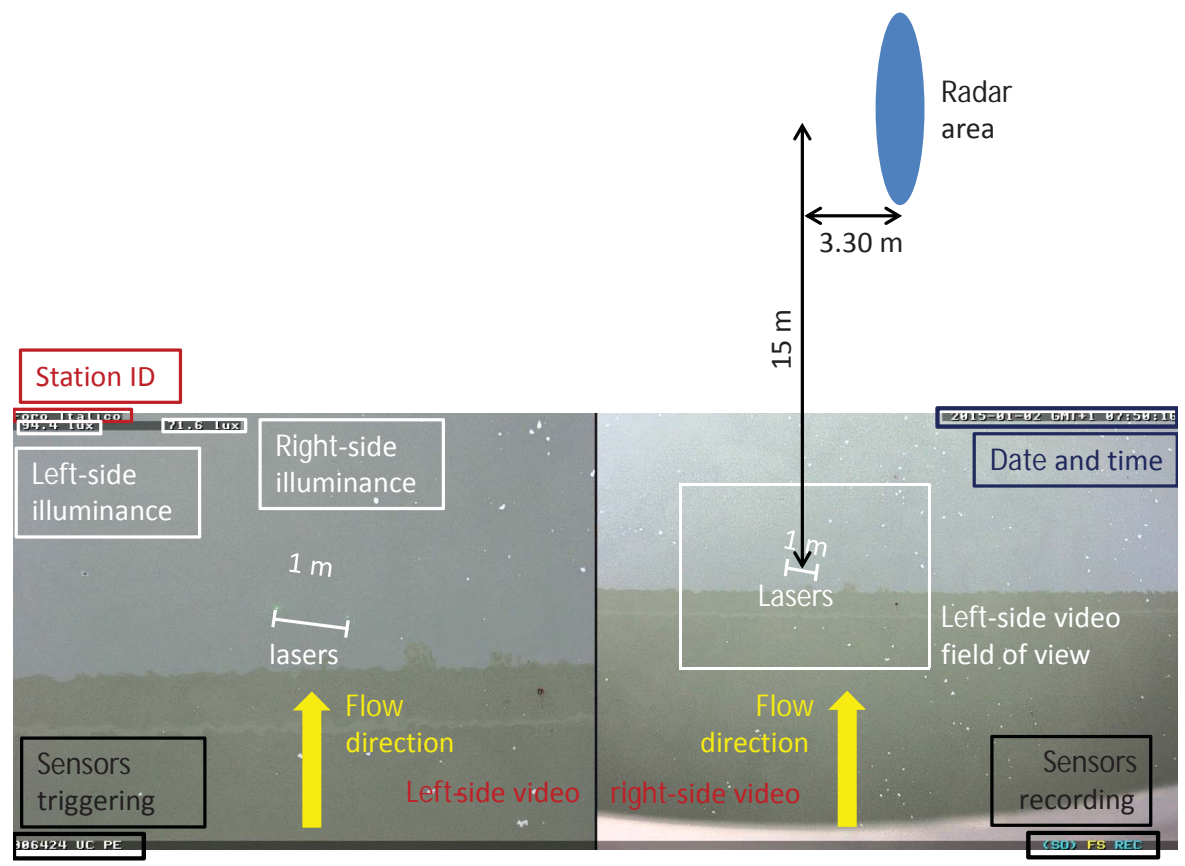

Figure 3. Representative experimental video frame captured from the gauge-cam station. Left: field of view recorded with the left-side optical sensor; right: with the right-side optical sensor. On the video frame captured with the right-side optical sensor, the field of view of the left-side video and the radar-focused area are also reported.

proach for non-invasive estimation of flow discharge in riverine environments. In this vein, the existing gauging station at Ponte del Foro Italico (which is regularly monitored by Centro Funzionale - Regione Lazio) has been empowered with optical sensors for a thorough validation and comparison of surface-flow velocity measurements. Although numerous technical contributions point out the advantage of using image-based technology against traditional instrumenta- tion (LeBoursicaud et al., 2015; Muste et al., 2011; Tauro, 2016), optical methodologies are scarcely used in engineering practice.

While several studies investigate the feasibility of using mobile (Dramais et al., 2011) and aerial optical platforms (Fujita and Hino, 2003; Fujita and Kunita, 2011; Tauro et al., 2015, 2016a) for enhanced versatility, stationary implementations should offer more consistent experi- 
mental settings. This results in simplified image preparation; for instance, image matching is rarely required before LSPIV processing of videos captured from stationary implementations (Tauro et al., 2014b). In the future, we plan on testing video data recorded at the gauge-cam station through an array of image-based algorithms, spanning from LSPIV to particle tracking velocimetry (Tang et al., 2008), long-term tracking (Pervez and Solomon, 1994), and optical flow (Quénot et al., 1998). In addition, classification of such a large database will leverage the application of unsupervised machine learning procedures (Tauro et al., 2014a).

We aim to investigate the feasibility of using fully autonomous optical methods for the kinematic characterization of surface flows over extended water bodies. As anticipated in (Tauro et al., 2014b) and further supported in this work, image-based algorithms such as LSPIV tend to be highly affected by varying flow settings. To overcome this issue, we plan on thoroughly studying the relationship between time variations of the velocity field and flow conditions. We will explore the effect of the following parameters on surfaceflow estimation: illumination conditions (this will be enabled by the camera built-in real-time light sensors), flow and meteorological conditions (hydrometeorological conditions are provided from the local gauging station), sediment loading, and floaters' visibility and space distribution.

Continuous and remote video acquisitions will also provide a comprehensive test bed for assessing the efficacy of optical methods in surface hydrology. Indeed, the availability of such a wide database will enable the quantification of uncertainty of image-based surface-flow measurements. We expect the gauge-cam station to aid in the definition of optimal operational settings for different optical algorithms. Optimal experimental conditions may be condensed in lumped indices to inform the use of optical methods in environmental settings.

\section{Case study}

The potential of the gauge-cam station to provide spatially distributed surface-flow velocity maps is demonstrated through the analysis of three videos recorded in January and February 2015. Specifically, we analyze two videos recorded on 2 January 2015, and one video captured on 7 February 2015. Data are freely available at 4TU.Centre for Research Data (2015). Details are reported in Table 1. The selected data set offers highly varying experimental conditions. Specifically, videos are captured in three sensibly different times of the day, i.e., early in the morning, and late and early in the afternoon. Illumination conditions are radically different, with a minimum of a few lux observed on 2 January at 17:10 LT, and a maximum of several thousands of lux observed on 7 February at 13:21 LT. While videos captured in January correspond to low-flow conditions, the video recorded on 7 February captures the rising limb of a mild high flow event. Naturally occurring circular white floaters ( 5 to $10 \mathrm{~cm}$ in diagonal) were scattered in the entire field of view for most of the recording time in the three videos.

\subsection{Image processing}

The surface-flow velocity field was reconstructed using two approaches: PTV and PIV. Prior to flow velocimetry, videos were prepared as follows. Video files in the MxPEG format were opened with the MxControlCenter camera propriety software and separate avi files were saved for the leftside and right-side optical sensors; see Fig. 4a and c for the video captured on 2 January at 07:50 LT. Such avi files were then decompressed into bmp $2048 \times 768$ pixels images using in-house codes for Matlab environment, and the acquisition frequency was computed for each video. On average, images reported herein were taken at $9.28 \mathrm{~Hz}$ by the Mobotix camera. Frame borders were then trimmed to obtain $1024 \times 768$ pixels images and the sole green channel was retained for analyses.

To emphasize lighter particles against a dark background, images were gamma corrected to darken midtones (Forsyth and Ponce, 2011); see Fig. 4d. Right-side optical sensor images were fish-eye undistorted using the Adobe Photoshop "Lens correction" filter (automatic geometric distortion correction with distort amount set to 88 and image size set to 82). Finally, both sets of images were processed by mean intensity subtraction to further highlight the presence of floaters against homogeneous backgrounds; see Fig. 4b and d. Image calibration was based on the lasers' trace onto the water surface. Calibration factors (to convert from pixel to metric velocities) were determined through calibration images, where the distance between lasers and the camera frame acquisition rate were taken as inputs.

Sequences of $1024 \times 768$ pixels bmp images from the left and right-side sensors were analyzed using PTVlab (Brevis et al., 2011). Particle detection was enabled through a Gaussian mask procedure (input parameters include correlation threshold, particle radius, and particle intensity threshold). Tracking was based on cross-correlation between pairs of subsequent images, whereby values for the interrogation area, minimum correlation, and similarity among neighbor parameters are reported in Table 2. Velocities along the current and perpendicular to the flow were computed at the nodes of a $10 \times 10$ pixels cell grid overlayed on images. Grids were computed for each image pair and then interpolated to obtain surface-flow velocity maps.

Particle image velocimetry was executed with the edPIV software (Gui, 2013) on the left- and right-side sequences of images. Tracers displayed in right-side sequences captured on 2 January, at 07:50 LT and at 17:10 LT presented minimal displacements between consecutive frames. Therefore, such sequences were subsampled to guarantee reliable correlation. For both sensors, images were resampled to reduce resolution to $640 \times 480$ pixels. Surface-flow velocity maps 
Table 1. Synoptic table for the set of analyzed videos.

\begin{tabular}{cccccc}
\hline Date & Time & $\begin{array}{c}\text { Illumination (left) } \\
\text { lux }\end{array}$ & $\begin{array}{c}\text { Illumination (right) } \\
\text { lux }\end{array}$ & $\begin{array}{c}\text { Water level } \\
\mathrm{m}\end{array}$ & $\begin{array}{c}\text { Radar velocity } \\
\mathrm{m} \mathrm{s}^{-1}\end{array}$ \\
\hline 2 January & $07: 50: 01$ to $07: 51: 01$ & $93.3-100.0$ & $70.8-76.7$ & 1.45 & 0.87 \\
2 January & $17: 10: 02$ to $17: 11: 02$ & $1.8-2.2$ & $1.3-1.7$ & 1.14 & 0.70 \\
7 February & $13: 21: 39$ to $13: 22: 39$ & $2291-6920$ & $1799-6920$ & 4.31 & 2.13 \\
\hline
\end{tabular}

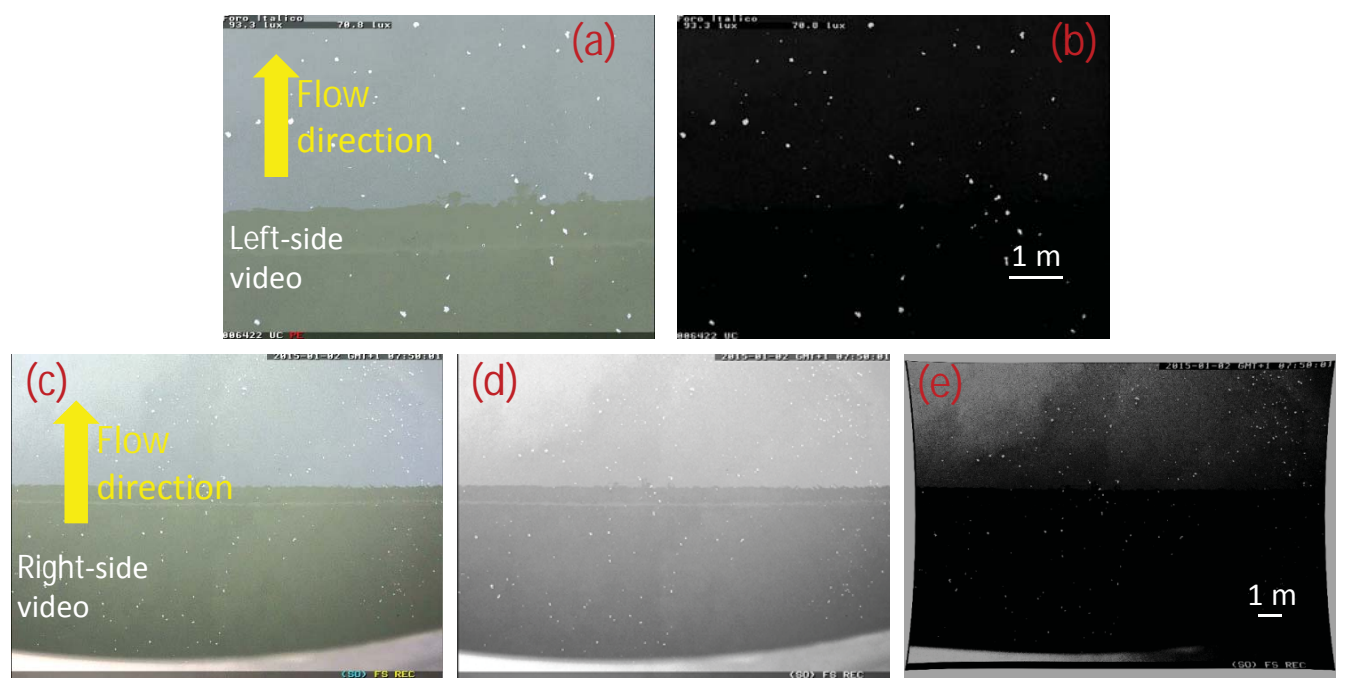

Figure 4. Image processing for left-side (a and $\mathbf{b}$ ) and right-side (c, $\mathbf{d}$, and e) videos captured on 2 January, at 07:50 LT. Left-side videos are (a) isolated and (b) filtered and midtone-corrected. Right-side videos are (c) isolated, (d) filtered, and (e) fish-eye undistorted and midtonecorrected.

were generated by averaging results in time. Input PTV and LSPIV parameters are reported for each case study in Table 2 .

\subsection{Velocimetry results}

Figure 5 displays LSPIV and PTV time-averaged maps for the left- and right-side videos captured on 2 January, at 07:50 LT. White areas in PTV maps are due to the absence of floating objects detected and tracked by the algorithm. As expected, the right-side PTV map, Fig. 5d, presents a higher density of tracked particles (and, therefore, smaller white areas) due to the larger field of view. Minimum, maximum, and average velocities are reported in Table 3 along with standard deviations. Such values are obtained by analyzing time-averaged maps in Fig. 5. On average, LSPIV results are much lower than PTV estimates. In addition, maps in Fig. 5a and $c$ are highly affected by illumination conditions. Indeed, both maps display extremely low velocities in the portion of the field of view that is directly exposed to light and is not covered by the bridge shadow. This effect is only partially mitigated in Fig. 5c, where the larger field of view results in slightly higher velocities even in regions lying outside the bridge shadow.
With respect to the left-side map, velocities computed by averaging over the entire field of view are equal to 0.35 and $0.83 \mathrm{~m} \mathrm{~s}^{-1}$ for the LSPIV and PTV analyses, respectively. Right-side velocities averaged over the entire region of interest are equal to 0.50 and $0.68 \mathrm{~m} \mathrm{~s}^{-1}$ for the LSPIV and PTV analyses, respectively. Compared to measurements from the RVM20 radar, PTV average velocities are closer to benchmark values than LSPIV results. This finding is in agreement with similar LSPIV implementations (Tauro et al., 2016c) in a smaller-scale mountainous stream.

In the scarce illumination conditions encountered in the video captured on 2 January, at 17:10 LT, both image-based algorithms lead to extremely low velocity values; see Table 3. High standard deviation in the right-side LSPIV analysis is attributed to inaccuracy in the correlation procedure due to the homogeneous dark background. High deviations in PTV analyses are instead related to the disappearance of the tracers during their transit in the field of view. Similarly, in the case of the excessive light sensed on 7 February, at 13:21 LT, left-side maps result in consistently underestimated velocities. In the case of right-side observations, both algorithms lead to unrealistically high average velocities and standard deviations. This behavior is likely related to the abundant wa- 
Table 2. Synoptic table for input PTV and LSPIV parameters. For each test, the following parameters are reported: number of analyzed images (no. images), image resolution (res.) and acquisition frequency (freq.), detection correlation threshold (corr. thresh.), radius, detection intensity threshold (inten. thresh.), interrogation area (int. area), minimum PTV correlation coefficient (min. corr.), neighbor similarity percentage (sim. neigh.), and LSPIV grid and interrogation window sizes (grid/wind. size).

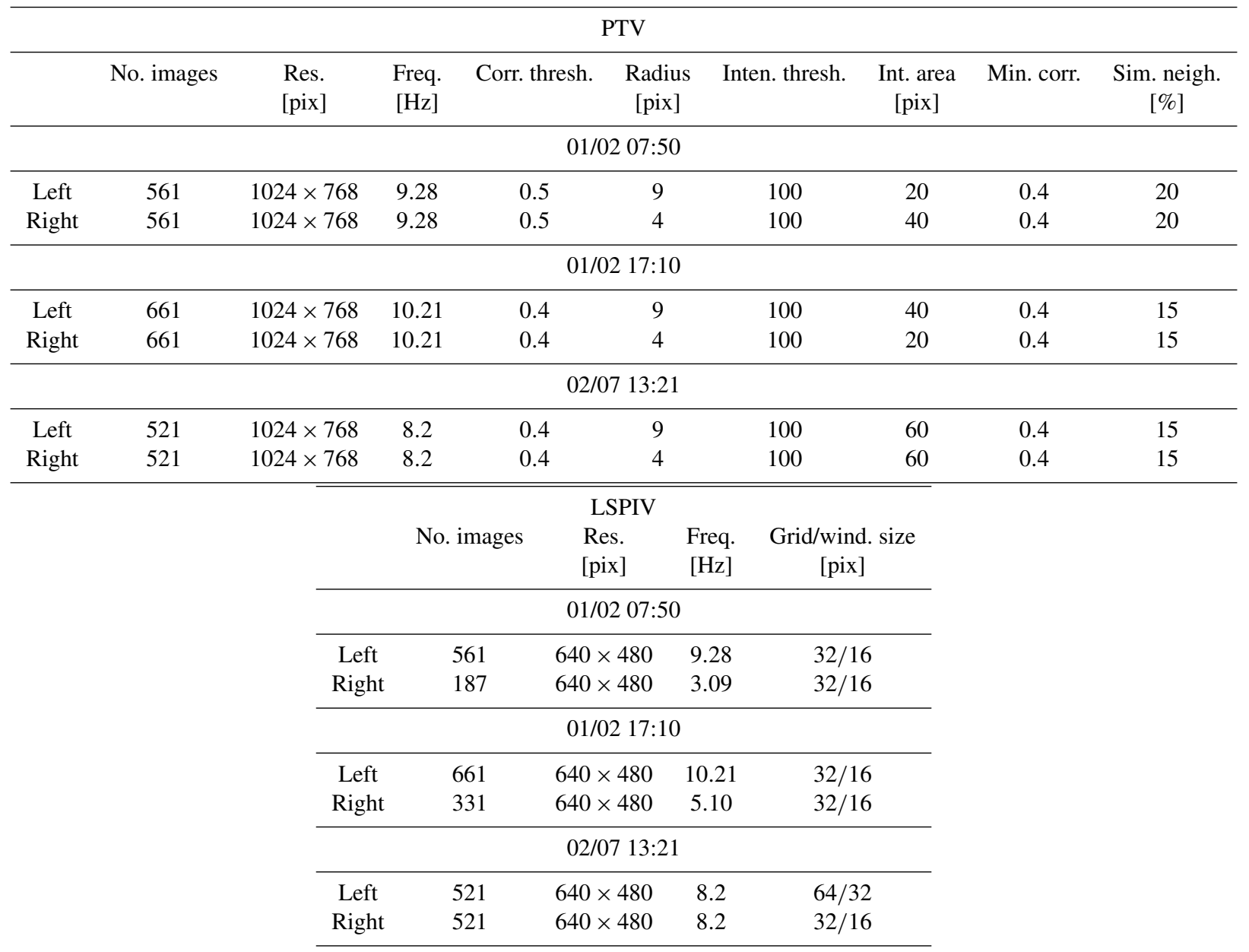

ter reflections that irregularly appear on the water surface and are erroneously treated as surface tracers by the algorithms.

\section{Discussion}

As supported by LSPIV and PTV analyses, the selected case studies present radically different experimental conditions. In particular, left-side velocities are generally closer to radar data than right-side recordings. This is attributed to several reasons. First, the right-side optical sensor captures a larger field of view but, on the negative side, it also introduces fisheye distortion. Undistorting images captured with the wideangle leads to image deformation and, therefore, increases uncertainties related to velocity estimation. Further, since a smaller number of pixels pertains to each floater in the rightside images, the visibility of the tracers is worsened. Finally, the top half of right-images is directly exposed to external illumination. In the case of particularly intense light, top re- gions present abundant noise due to water reflections that tend to "mask" the presence of tracers.

Critical illumination severely affects LSPIV analyses. Specifically, LSPIV processing results either in velocity estimates considerably lower than radar measurements and PTV values, or in unrealistically high values. Left-side recordings analyzed through LSPIV lead to extremely low values, less than one-tenth radar velocities, whereas right-side videos yield velocity overestimations, up to twice radar velocities. This fact is consistent with previous studies (Tauro et al., 2014b, 2016b), and is mainly attributed to the high sensitivity of LSPIV to illumination conditions and to the irregular presence and distribution of floaters in the field of view (Tauro et al., 2016b). In the video captured early in the morning, the river mirror-like surface is highly detrimental for velocity estimation. Further, the negative influence of reflections is exacerbated in the video captured early in the afternoon, whereby abundant and irregular reflections yield unrealistic 

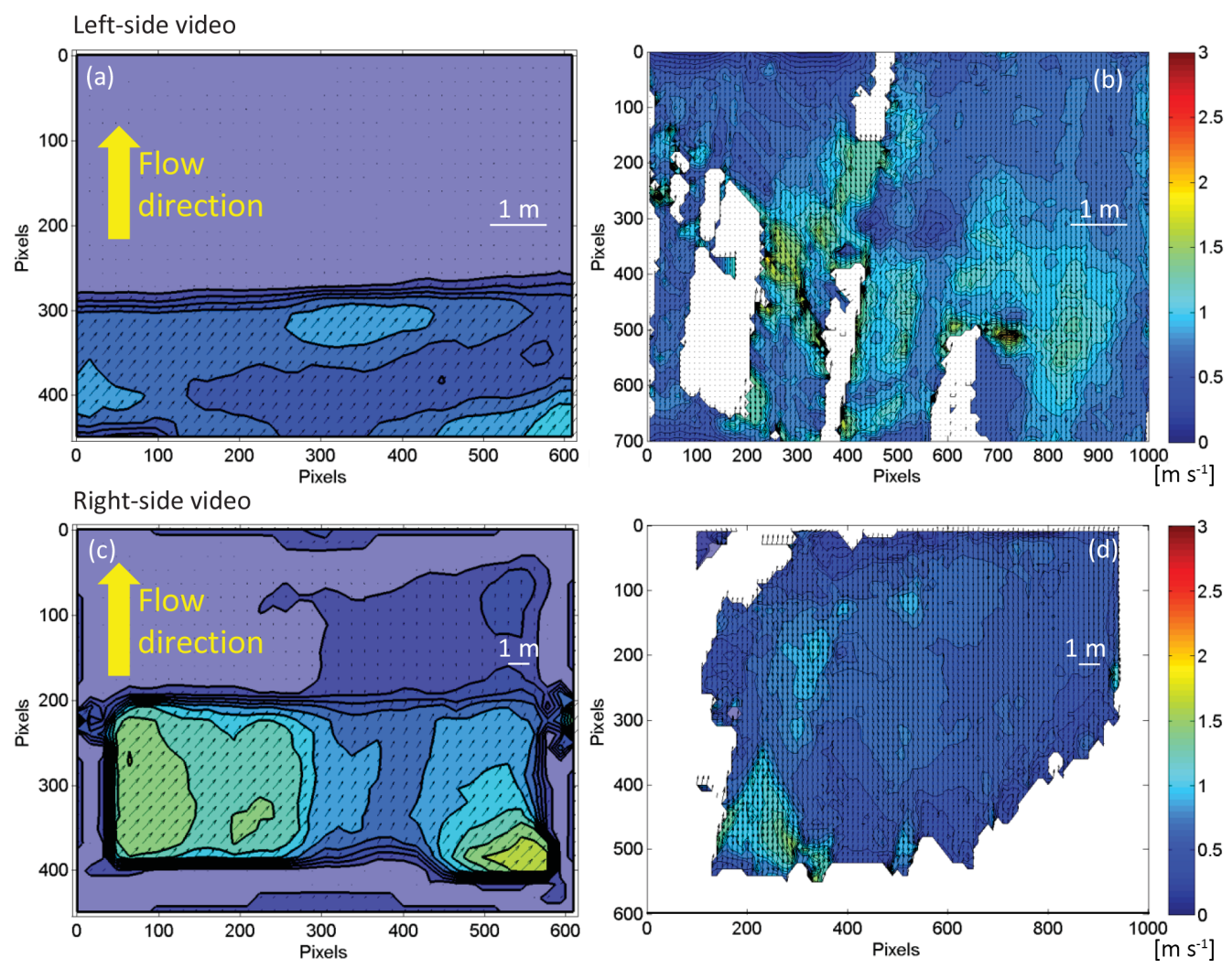

Figure 5. Experimental findings for the video captured at 07:50 LT on 2 January: (a) LSPIV time-averaged map, (b) PTV time-averaged map for the left-side video, (c) LSPIV time-averaged map, and (d) PTV time-averaged map for the right-side video. Image resolution is decreased from $1024 \times 768$ pixels to $640 \times 480$ pixels for LSPIV processing. White areas in panels (b) and (d) are due to the absence of detected and tracked particles. Black arrows depict velocity vectors. Vectors in panels (a) and (c) are magnified by a factor of 2 to improve readability.

flow velocities. In addition, the irregular size of the floaters and their discontinuous transit increase the uncertainty of LSPIV estimates. According to Tauro et al. (2016c), velocity estimation closer to real values may be obtained by analyzing only image sequences depicting the continuous and spatially homogeneous occurrence of tracers.

On the other hand, in the case of the video captured early in the morning, PTV findings are promising and in agreement with radar velocities, within a $20 \%$ difference. In particular, estimates obtained from the left-side video are close to radar data, whereas the average velocity decreases in the right-side video, due to poorer floaters' visibility and to uncertainties in fish-eye removal. Based on our findings, PTV could serve as a good alternative to LSPIV in case of spatially inhomogeneous tracer seeding.

However, both algorithms are severely impacted by adverse illumination conditions. In the case of scarce light, the visibility of floaters is hampered; on the other hand, in case of excessive light, surface reflections of the same size of the floaters' may be erroneously regarded as tracers, thus leading to unrealistic velocities. Such criticalities may be mitigated by integrating polarizers and filters in the gauge-cam station.
This preliminary study demonstrates the versatility of the gauge-cam station and its advantages with respect to traditional instrumentation. Specifically, in the first semester of 2015 , almost $1 \mathrm{~Tb}$ of data have been recorded for a total of more than $400 \mathrm{~h}$ of high-quality videos. This extremely rich database depicts the surface flow of the Tiber River for a multitude of variable illumination conditions (from 2 to almost 7000 lux) and flow regimes (for instance, two flood events occurred in February and April). Throughout the operation of the gauge-cam station, minimal maintenance and operational costs were required for supplying power, hard disk periodic replacement, and internet connectivity. Compared to traditional flow velocity instrumentation, the apparatus enables fully remote measurements over a wide range of velocities: due to the large field of view captured by the right-side optical sensor, velocities up to few meters per second can be reconstructed. Further, the system of lasers enables remote image calibration in case of variable flow conditions.

Conversely, a standard procedure for operating the gaugecam station and handling video data is yet to be achieved. The mirror-like surface of the Tiber River at this particular location poses several problems to the application of correlationbased algorithms. Further, the rather extended cross section 
Table 3. Synoptic table of the statistics for time-averaged velocity maps. Values indicate minimum $\left(v_{\min }\right)$, maximum $\left(v_{\max }\right)$, mean $(\bar{v})$ velocities, and standard deviations $\left(\sigma_{\mathrm{V}}\right)$ computed over timeaveraged maps, and radar velocity $\left(v_{\mathrm{R}}\right)$.

\begin{tabular}{|c|c|c|c|c|c|}
\hline & $\underset{\left[\mathrm{m} \mathrm{s}^{-1}\right]}{v_{\min }}$ & $\begin{array}{c}v_{\max } \\
{\left[\mathrm{m} \mathrm{s}^{-1}\right]}\end{array}$ & {$\left[\begin{array}{c}\bar{v} \\
{\left[\mathrm{~m} \mathrm{~s}^{-1}\right]}\end{array}\right.$} & $\begin{array}{c}\sigma_{\mathrm{V}} \\
{\left[\mathrm{m} \mathrm{s}^{-1}\right]}\end{array}$ & $\begin{array}{c}v_{\mathrm{R}} \\
{\left[\mathrm{m} \mathrm{s}^{-1}\right]}\end{array}$ \\
\hline \multicolumn{5}{|c|}{ 01/02 07:50 } & 0.87 \\
\hline Left & & & & & \\
\hline PTV & 0 & 2.96 & 0.83 & 0.28 & \\
\hline LSPIV & 0 & 1.40 & 0.35 & 0.40 & \\
\hline \multicolumn{6}{|l|}{ Right } \\
\hline PTV & 0 & 2.07 & 0.77 & 0.18 & \\
\hline LSPIV & 0 & 1.94 & 0.57 & 0.58 & \\
\hline \multicolumn{5}{|c|}{ 01/02 17:10 } & 0.69 \\
\hline Left & & & & & \\
\hline PTV & 0 & 2.30 & 0.35 & 0.40 & \\
\hline LSPIV & 0 & 0.84 & 0.07 & 0.14 & \\
\hline \multicolumn{6}{|l|}{ Right } \\
\hline PTV & 0 & 4.15 & 0.30 & 0.53 & \\
\hline LSPIV & 0 & 3.45 & 1.38 & 1.54 & \\
\hline \multicolumn{5}{|c|}{ 02/07 13:21 } & 2.13 \\
\hline Left & & & & & \\
\hline PTV & 0.16 & 2.09 & 1.33 & 0.19 & \\
\hline LSPIV & 0.01 & 0.23 & 0.16 & 0.04 & \\
\hline \multicolumn{6}{|l|}{ Right } \\
\hline PTV & 0.06 & 8.49 & 2.23 & 1.13 & \\
\hline LSPIV & 0 & 4.49 & 2.38 & 1.64 & \\
\hline
\end{tabular}

hinders efficient artificial seeding. Such criticalities will demand advanced image enhancement to highlight the presence of traceable objects. Another considerable limitation toward a fully unsupervised operation of the gauge-cam station is the proprietary video encoder, which requires the use of the dedicated camera software, thereby preventing rapid data analysis. In this respect, several video formats and encoders will be tested to facilitate image extraction. Finally, a user-friendly platform will be developed for the generation of surface-flow velocity maps and quick comparison to radar data.

\section{Conclusions}

In this paper, we presented a novel fixed gauge-cam station for flow velocity observations in riverine settings. The station is based on the remote acquisition and calibration of high quality images. Maps of the surface velocity field were generated over extended areas up to $20.6 \times 15.5 \mathrm{~m}^{2}$ by applying optics-based algorithms on video data. Since December 2014, the station has allowed for the recording of more than $1 \mathrm{~Tb}$ of video data. In three representative case studies, we analyzed 1 min videos through two different optics-based techniques: LSPIV and PTV. As expected from previous studies, both approaches are highly influenced by illumination conditions. In case of non-adverse external light, LSPIV underestimates surface flow, while PTV measurements are in agreement with radar data.

The proposed installation offers a viable platform for thorough testing and validation of image-based algorithms under a wide array of variable illumination and flow conditions. In future studies, we plan on investigating the optimal operational settings for several vision approaches, including LSPIV, PTV, optical flow, and machine learning. Particular care will be devoted to the analysis of flood events during which river velocity estimations may be particularly challenging.

\section{Data availability}

Research data are freely available at doi:10.4121/uuid:68ef90c2-d9da-4511-a7ba-d21f68769e03.

Acknowledgements. This work was supported by the Ministero degli Affari Esteri project 2015 Italy-USA PGR00175 and by the UNESCO Chair in Water Resources Management and Culture.

Edited by: A. Benedetto

\section{References}

4TU - Centre for Research Data: Gauge-cam videos of river flow of the Tiber river - part 1, doi:10.4121/uuid:68ef90c2-d9da-4511a7ba-d21f68769e03, 2015.

Admiraal, D., Stansbury, J., and Haberman, C.: Case study: particle velocimetry in a model of lake Ogallala, J. Hydraul. Eng., 130, 599-607, 2004.

Adrian, R. J.: Particle-imaging techniques for experimental fluidmechanics, Ann. Rev. Fluid Mech., 23, 261-304, 1991.

Alessandrini, V., Bernardi, G., and Todini, E.: An operational approach to real-time dynamic measurement of discharge, Hydrol. Res., 44, 953-964, 2013.

Bechle, A., Wu, C., Liu, W., and Kimura, N.: Development and application of an automated river-estuary discharge imaging system, J. Hydraul. Eng., 138, 327-339, 2012.

Bradley, A. A., Kruger, A., Meselhe, E. A., and Muste, M. V. I.: Flow measurement in streams using video imagery, Water Resour. Res., 38, 1-8, 2002.

Brevis, W., Niño, Y., and Jirka, G. H.: Integrating cross-correlation and relaxation algorithms for particle tracking velocimetry, Exp. Fluids, 50, 135-147, 2011.

Chiu, C.-L.: Application of entropy concept in open-channel flow study, J. Hydraul. Eng., 117, 615-628, 1991.

Costa, J. E., Cheng, R. T., Haeni, F. P., Melcher, N., Spicer, K. R., Hayes, E., Plant, W., Hayes, K., Teague, C., and Barrick, D.: Use of radars to monitor stream discharge by noncontact methods, 
Water Resour. Res., 42, W07422, doi:10.1029/2005WR004430, 2006.

Creutin, J. D., Muste, M., Bradley, A. A., Kim, S. C., and Kruger, A.: River gauging using PIV techniques: a proof of concept experiment on the Iowa River, J. Hydrol., 277, 182-194, 2003.

Dermisis, D. C. and Papanicolaou, A. N.: Fish passage over hydraulic structures in Midwestern Rivers of the USA, Int. J. River Basin Manage., 7, 313-328, 2009.

Dramais, G., LeCoz, J., Camenen, B., and Hauet, A.: Advantages of a mobile LSPIV method for measuring flood discharges and improving stage-discharge curves, J. Hydro-Environ. Res., 5, 301312, 2011.

Farina, G., Alvisi, S., Franchini, M., and Moramarco, T.: Three methods for estimating the entropy parameter $M$ based on a decreasing number of velocity measurements in a river crosssection, Entropy, 16, 2512-2529, 2014.

Forsyth, D. A. and Ponce, J.: Computer Vision: a Modern Approach, Prentice Hall, NJ, 114-120, 2011.

Fujita, I. and Hino, T.: Unseeded and seeded PIV measurements of river flows video from a helicopter, J. Visual., 6, 245-252, 2003.

Fujita, I. and Kunita, Y.: Application of aerial LSPIV to the 2002 flood of the Yodo River using a helicopter mounted high density video camera, J. Hydro-Environ. Res., 5, 323-331, 2011.

Fujita, I., Muste, M., and Kruger, A.: Large-scale particle image velocimetry for flow analysis in hydraulic engineering applications, J. Hydraul. Res., 36, 397-414, 1997.

Fulton, J. and Ostrowski, J.: Measuring real-time streamflow using emerging technologies: radar, hydroacoustics, and the probability concept, J. Hydrol., 357, 1-10, 2008.

Gui, L.: EDPIV - Evaluation Software for Digital Particle Image Velocimetry, http://lcgui.net (last access: November 2015), 2013.

Hauet, A., Creutin, J. D., and Belleudy, P.: Sensitivity study of largescale particle image velocimetry measurement of river discharge using numerical simulation, J. Hydrol., 349, 178-190, 2008a.

Hauet, A., Kruger, A., Krajewski, W., Bradley, A., Muste, M., Creutin, J., and Wilson, M.: Experimental system for real-time discharge estimation using an image-based method, J. Hydrol. Eng., 13, 105-110, 2008b.

Hauet, A., Muste, M., and Ho, H.-C.: Digital mapping of riverine waterway hydrodynamic and geomorphic features, Earth Surf. Process. Landf., 34, 242-252, 2009.

Hrachowitz, M., Savenije, H. H. G., Blöschl, G., McDonnell, J. J., Sivapalan, M., Pomeroy, J. W., Arheimer, B., Blume, T., Clark, M. P., Ehret, U., Fenicia, F., Freer, J. E., Gelfan, A., Gupta, H. V., Hughes, D. A., Hut, R. W., Montanari, A., Pande, S., Tetzlaff, D., Troch, P. A., Uhlenbrook, S., Wagener, T., Winsemius, H. C., Woods, R. A., Zehe, E., and Cudennec, C.: A decade of predictions in ungauged basins (PUB) - a review, Hydrol. Sci. J., 58, 1198-1255, 2013.

http://www.apinex.com (last access: 14 June 2016), GM-CW02, 2015.

Jodeau, M., Hauet, A., Paquier, A., Le Coz, J., and Dramais, G.: Application and evaluation of LS-PIV technique for the monitoring of river surface velocities in high flow conditions, Flow Meas. Instr., 19, 117-127, 2008.

Kantoush, S. A., Schleiss, A. J., Sumi, T., and Murasaki, M.: LSPIV implementation for environmental flow in various laboratory and field cases, J. Hydro-Environ. Res., 5, 263-276, 2011.
Kim, Y., Muste, M., Hauet, A., Krajewski, W. F., Kruger, A., and Bradley, A.: Stream discharge using mobile large-scale particle image velocimetry: A proof of concept, Water Resour. Res., 44, W09502, doi:10.1029/2006WR005441, 2008.

LeBoursicaud, R., Pénard, L., Hauet, A., Thollet, F., and LeCoz, J.: Gauging extreme floods on YouTube: application of LSPIV to home movies for the post-event determination of stream discharges, Hydrol. Process., 30, 90-105, 2015.

LeCoz, J., Hauet, A., Pierrefeu, G., Dramais, G., and Camenen, B.: Performance of image-based velocimetry LSPIV applied to flash-flood discharge measurements in Mediterranean rivers, J. Hydrol., 394, 42-52, 2010.

Montanari, A., Young, G., Savenije, H., Hughes, D., Wagener, T., Ren, L., Koutsoyiannis, D., Cudennec, C., Grimaldi, S., Bloeschl, G., Sivapalan, M., Beven, K., Gupta, H., Arheimer, B., Huang, Y., Schumann, A., Post, A., Srinivasan, V., Boegh, E., Hubert, P., Harman, C., Thompson, S., Rogger, M., Hipsey, M., Toth, E., Viglione, A., DiBaldassarre, G., Schaefli, B., McMillan, H., Schymanski, S., Characklis, G., Yu, B., Pang, Z., and Belyaev, V.: Panta Rhei - Everything Flows: Change in hydrology and society - The IAHS Scientific Decade 2013-2022, Hydrol. Sci. J., 58, 1256-1275, 2013.

Moramarco, T., Saltalippi, C., and Singh, V. P.: Estimation of mean velocity in natural channels based on Chiu's velocity distribution equation, J. Hydrol. Eng., 9, 42-50, 2004.

Muste, M., Fujita, I., and Hauet, A.: Large-scale particle image velocimetry for measurements in riverine environments, Water Resour. Res., 44, W00D19, doi:10.1029/2008WR006950, 2008.

Muste, M., Ho, H.-C., and Kim, D.: Considerations on direct stream flow measurements using video imagery: Outlook and research needs, J. Hydro-Environ. Res., 5, 289-300, 2011.

Pervez, M. S. and Solomon, T. H.: Long-term tracking of neutrally buoyant tracer particles in two-dimensional fluid flows, Exp. Fluids, 17, 135-140, 1994.

Quénot, G. M., Pakleza, J., and Kowalewski, T. A.: Particle image velocimetry with optical flow, Exp. Fluids, 25, 177-189, 1998.

Raffel, M., Willert, C. E., Wereley, S. T., and Kompenhans, J.: Particle Image Velocimetry. A practical guide, Springer, New York, 2007.

Tang, H. W., Chen, C., Chen, H., and Huang, J. T.: An improved PTV system for large-scale physical river model, J. Hydrodynam., 20, 669-678, 2008.

Tauro, F.: Particle tracers and image analysis for surface flow observations, WIREs Water, 3, 25-39, 2016.

Tauro, F., Grimaldi, S., Petroselli, A., and Porfiri, M.: Fluorescent particle tracers for surface flow measurements: a proof of concept in a natural stream, Water Resour. Res., 48, W06528, doi:10.1029/2011WR011610, 2012a.

Tauro, F., Grimaldi, S., Petroselli, A., Rulli, M. C., and Porfiri, M.: Fluorescent particle tracers in surface hydrology: a proof of concept in a semi-natural hillslope, Hydrol. Earth Syst. Sci., 16, 2973-2983, doi:10.5194/hess-16-2973-2012, 2012b.

Tauro, F., Grimaldi, S., and Porfiri, M.: Unraveling flow patterns through nonlinear manifold learning, PLoS ONE, 9, e91131, 2014a.

Tauro, F., Porfiri, M., and Grimaldi, S.: Orienting the camera and firing lasers to enhance large scale particle image velocimetry for streamflow monitoring, Water Resour. Res., 50, 7470-7483, 2014b. 
Tauro, F., Pagano, C., Phamduy, P., Grimaldi, S., and Porfiri, M.: Large scale particle image velocimetry from an unmanned aerial vehicle, IEEE/ASME T. Mechatron., 20, 3269-3275, 2015.

Tauro, F., Porfiri, M., and Grimaldi, S.: Surface flow measurements from drones, J. Hydrol., doi:10.1016/j.jhydrol.2016.06.012, 2016a.

Tauro, F., Olivieri, G., Petroselli, A., Porfiri, M., and Grimaldi, S.: Flow monitoring with a camera: A case study on a flood event in the Tiber River, Environ. Monit. Assess., 188, 118, $2016 \mathrm{~b}$.

Tauro, F., Petroselli, A., and Arcangeletti, E.: Assessment of dronebased surface flow observations, Hydrol. Process., 30, 11141130, 2016c.
Tazioli, A.: Experimental methods for river discharge measurements: comparison among tracers and current meter, Hydrol. Sci J., 56, 1314-1324, 2011.

Tsubaki, R., Fujita, I., and Tsutsumi, S.: Measurement of the flood discharge of a small-sized river using an existing digital video recording system, J. Hydro-Environ. Res., 5, 313-321, 2011.

CAE S.p.a.: www.cae.it, last access: 14 June 2016.

Mobotix: www.mobotix.com, last access: 14 June 2016. 